Subscriber access provided by b-on / UNIVERSIDADE DO MINHO

\title{
Article
}

\section{Tuning the stiffness of surfaces by assembling genetically engineered polypeptides with tailored amino acid sequence}

Rui R. Costa, Miguel González-Pérez, Marcos Herrero-Gutiérrez, Ricardo A. Pires, Matilde Alonso, J. Carlos Rodriguez-Cabello, Rui L. Reis, and Iva Pashkuleva

Biomacromolecules, Just Accepted Manuscript • DOI: 10.1021/acs.biomac.8b00723 • Publication Date (Web): 03 Jul 2018

Downloaded from http://pubs.acs.org on July 4, 2018

\section{Just Accepted}

"Just Accepted" manuscripts have been peer-reviewed and accepted for publication. They are posted online prior to technical editing, formatting for publication and author proofing. The American Chemical Society provides "Just Accepted" as a service to the research community to expedite the dissemination of scientific material as soon as possible after acceptance. "Just Accepted" manuscripts appear in full in PDF format accompanied by an HTML abstract. "Just Accepted" manuscripts have been fully peer reviewed, but should not be considered the official version of record. They are citable by the Digital Object Identifier (DOI®). "Just Accepted" is an optional service offered to authors. Therefore, the "Just Accepted" Web site may not include all articles that will be published in the journal. After a manuscript is technically edited and formatted, it will be removed from the "Just Accepted" Web site and published as an ASAP article. Note that technical editing may introduce minor changes to the manuscript text and/or graphics which could affect content, and all legal disclaimers and ethical guidelines that apply to the journal pertain. ACS cannot be held responsible for errors or consequences arising from the use of information contained in these "Just Accepted" manuscripts. 


\title{
Tuning the stiffness of surfaces by assembling
}

\section{genetically engineered polypeptides with tailored}

\section{amino acid sequence}

\author{
Rui R. Costa, ${ }^{* \dagger, t+}$ Miguel González-Pérez, ${ }^{\S, \|}$ Marcos Herrero-Gutiérrez, ${ }^{\S, \|}$ Ricardo A. Pires, ${ }^{\dagger, t, L}$ \\ Matilde Alonso, ${ }^{\S, \|}$ J. Carlos Rodriguez-Cabello, ${ }^{\S, \|}$ Rui L. Reis, ${ }^{\dagger, t,\llcorner}$ and Iva Pashkuleva* ${ }^{* \dagger, t}$ \\ †3B's Research Group, I3Bs - Research Institute on Biomaterials, Biodegradables and \\ Biomimetics, University of Minho, Headquarters of the European Institute of Excellence on \\ Tissue Engineering and Regenerative Medicine, AvePark, Parque de Ciência e Tecnologia, Zona \\ Industrial da Gandra, 4805-017 Barco, Guimarães, Portugal
}

${ }^{\ddagger}$ ICVS/3B’s, PT Government Associated Laboratory, Braga/Guimarães, Portugal

${ }^{\S}$ G.I.R. Bioforge, University of Valladolid, CIBER-BBN, Edificio LUCIA, Paseo de Belén, 19, 47011, Valladolid, Spain

"Networking Research Center on Bioengineering, Biomaterials and Nanomedicine (CIBERBBN), Valladolid, Spain

${ }^{\llcorner}$The Discoveries Centre for Regenerative and Precision Medicine, Headquarters at University of Minho, Avepark, 4805-017 Barco, Guimarães, Portugal 


\begin{abstract}
We introduce elastin-like recombinamers (ELRs) as polypeptides with precise amino acid positioning to generate polypeptide coatings with tunable rigidity. Two ELRs are used: V84ELR, a hydrophobic monoblock, and EI-ELR, an amphiphilic diblock. Both were modified with the amine-reactive tetrakis (hydroxymethyl) phosphonium chloride compound. We evaluated the affinity, the conformation, and the dissipative behavior of ELRs assembled on alkanethiol selfassembled coatings by quartz crystal microbalance with dissipation monitoring, multi-parametric surface plasmon resonance, and atomic force microscopy. The thickness of the polypeptide coatings showcase the preferential affinity of ELRs to $\mathrm{NH}_{2}$ and $\mathrm{CH}_{3}$ terminated surfaces. We demonstrate that V84-ELR strongly bonded to the substrate and reorganizes into an extended and more hydrated layer as the adsorbed amount increases, whereas EI-ELR has a less dissipative behavior. The results suggest that ELR adsorption depends on the amino acid sequence and the substrate chemistry, ultimately influencing the stiffness of the polypeptide coatings.
\end{abstract}

KEYWORDS. Elastin-like recombinamers, Surface modification, Quartz-crystal microbalance, Multi-parametric surface plasmon resonance, Biomaterials

\title{
INTRODUCTION
}

Protein adsorption is a common method employed to modify the properties of a surface. It is driven by different supramolecular forces such as van der Waals, hydrophobic, electrostatic interactions, and hydrogen bonding, and depends on the structure and biochemical properties of the protein. ${ }^{1-3}$ Besides their native diversity, custom-made peptides and proteins with tailored amino acid sequences are also routinely synthesized by chemical or recombinant techniques, 
thus, increasing the proteins' variety. The existence of a huge variety of proteins brings difficulties in predicting their binding affinity and orientation, and has led to the development of highly specialized techniques and simulation models to determine the mechanistic details of protein adsorption. ${ }^{4-8}$ Understanding how different classes of proteins adsorb to different substrates is thus an imperative prerequisite to foresee the physicochemical aspects and functionality of protein-based layers and films.

The ability of structural modulation and the diversification in terms of bioactivity have stimulated huge research interest in protein modified surfaces for biomedical, pharmaceutical, and tissue engineering applications. In all these applications, protein adsorption is usually aiming at enhancing the surface biocompatibility, ${ }^{9}$ including alternation of the surface chemical composition and also changing superficial physical characteristics. As examples, collagen ${ }^{10}$ and silk $^{11}$ have significantly different modulus (in the order of MPa and GPa, respectively), indicating that tailoring the amino acid sequence of proteins might grant control not only over the chemistry of a surface coating made by these proteins but also of the coating's rigidity. In this work we used customized elastin-like recombinamers (ELRs) to study the effect of amino acids positioning and distribution within a protein on the stiffness of thin coatings made from this protein. ELRs are recombinant and stimuli-responsive polypeptides that mimic natural elastin, the extracellular elastic protein found in tissues and organs that require elasticity to function. ELRs are based on the repeating pentapeptide valine-proline-glycine- $X$-glycine (VPGXG) or equivalently to any of the five cyclic permutations (e.g., GXGVP), where $X$ represents any natural or artificial amino acid. ${ }^{12-15}$ In aqueous solution, they exhibit a transition temperature $\left(T_{t}\right)$, below which free polymer chains are soluble hydrated random coils. Above $T_{t}$, the polymer chains fold into a regular $\beta$-spiral structure, resulting in a phase-separated state. This 
phenomenon is called inverse temperature transition (ITT). One of the most attractive properties of ELRs is their recombinant nature, which allows the insertion of single amino acids, polar or nonpolar, and sequences with bioactivity. In fact, ELRs with RGD,${ }^{16} \mathrm{REDV}^{17}$ and biomineralization ${ }^{18}$ sequences were explored previously, thus showcasing the possibility to assemble films with highly specific physical, chemical and biological properties.

Herein, we rely on a combination of specialized surface analysis tools to investigate the adsorption of hydrophobic and amphiphilic ELRs onto self-assembled monolayers (SAMs) made of alkanethiols terminated with $\mathrm{CH}_{3}, \mathrm{OH}, \mathrm{COOH}$, and $\mathrm{NH}_{2}$. Quartz crystal microbalance with dissipation monitoring (QCM-D), ${ }^{19-21}$ multi-parametric surface plasmon resonance (MP-SPR), ${ }^{22-}$ 24 and atomic force microscopy (AFM $)^{25-27}$ have been shown to be sensitive instruments in evaluating the affinity, and the conformation of polymer on surfaces (including proteins), as well as the dissipative behavior of the assembled films. Both the QCM-D and MP-SPR monitor the deposition of mass on planar surfaces in real time, molecular interactions, and layer properties. Whereas the QCM-D is an acoustic method highly sensitive to a film's shear modulus and hydration, the MP-SPR is an optical method that is almost not affected by coupled water or conformational changes. Allied with the imaging capabilities of AFM, we describe the adsorption of ELRs onto SAMs with different chemistries. Furthermore, we discuss how different ELR architectures and amino acid sequences can generate polypeptide coatings with tunable dissipative behavior.

\section{MATERIALS AND METHODS.}

Materials. 1-Dodecanethiol (ref. 471364), 11-mercapto-1-undecanol 99\% (ref. 674249), 12mercaptododecanoic acid 96\% (ref. 675067), 11-amino-1-undecanethiol hydrochloride (ref. 
674397), and phosphate buffered saline (ref. P4417) were purchased from Sigma-Aldrich. Ammonium hydroxide solution (ref. 05002) was purchased from VWR, and hydrogen peroxide was purchased from Enzymatic (ref. 141076). Two custom-made ELRs were ordered from Technical Protein Nanobiotechnology S.L. (Valladolid, Spain). The amino acid sequences of the different constructs are (i) $\mathrm{MGKKKP}(\mathrm{VPGVG})_{84} \mathrm{~V}$ (theoretical molecular weight: $35191 \mathrm{Da}$ ), and (ii) $\mathrm{MGKKKP}\left[(\mathrm{VPGVG})_{2}(\mathrm{VPGEG})(\mathrm{VPGVG})_{2}\right]_{10}(\mathrm{VGIPG})_{60} \mathrm{~V}$ (theoretical molecular weight: $46981 \mathrm{Da}$ ), respectively. A representation of their structures can be found in Figure 1. Tetrakis(hydroxymethyl) phosphonium chloride was purchased from Acros Organics (ca. 80\% solution in water, ref. 389441000). Gold-coated AT-cut quartz sensors (ref. AWS SNS 000043 A) were acquired from AWSensors (Spain), and MP-SPR gold-coated sensors ( $\sim 50 \mathrm{~nm})$ with a chromium adhesion layer ( $\sim 2 \mathrm{~nm}$ ) (ref. SPR102-AU) were obtained from BioNavis (Finland).

Characterization and modification of the ELRs. The unmodified ELRs were bonded with THPC, after which they were designated as V84-ELR and EI-ELR, respectively, for simplicity sake. The modification was made as follows: A solution of THPC (to unmodified V84-ELR: $0.0852 \mathrm{mmol}, 60$ eq.; to unmodified EI-ELR: $0.0639 \mathrm{mmol}$ ) was added to a solution of the asreceived ELRs in DMF (0.00142 $\mathrm{mmol}$ or $0.00107 \mathrm{mmol}$, respectively, in $5 \mathrm{~mL}$ ). The resulting mixture was stirred at room temperature for $60 \mathrm{~h}$. After this time, diethyl ether $(25 \mathrm{~mL})$ was added to the mixture to yield a white precipitate. The supernatant was removed and the solid was washed with acetone $(3 \times 15 \mathrm{~mL})$ with centrifugation $(12500 \mathrm{G}, 10 \mathrm{~min})$, dried under reduced pressure, redissolved in cold MilliQ water $\left(4^{\circ} \mathrm{C}\right)$, dialyzed against MilliQ water $(3 \times 25 \mathrm{~L})$, filtered and lyophilized. The purity, molecular weight, and transition temperature of the acquired batches were routinely determined by amino acid composition determination, matrix-assisted laser desorption/ionization time-of-flight (MALDI-TOF) and dynamic laser scattering (DLS). 
Amino acid composition determination was previously used to assess the composition of ELRs ${ }^{17}$ (Table S1). MALDI-TOF mass spectroscopy was performed in a Voyager STR, from Applied Biosystems, in linear mode and with an external calibration using bovine serum albumin (BSA). DLS measurements were conducted using a Nano-ZS zeta-sizer from Malvern (United Kingdom) to determine the hydrodynamic size. Aqueous samples of each ELR were prepared at $100 \mu \mathrm{g} \cdot \mathrm{mL}^{-1}$ in PBS, $\mathrm{pH}$ 7.4. Measurements were performed at incremental temperatures from 4 ${ }^{\circ} \mathrm{C}$ to $40{ }^{\circ} \mathrm{C}$ after a stabilization time of $5 \mathrm{~min}$. The number of runs was set to automatic (10-100 runs) and the scattering angle was configured for non-invasive back scatter mode (NIBS, at $\left.173^{\circ}\right)$.

Preparation of alkanethiol SAMs for ELR assembly. Gold-coated AT-quartz and MP-SPR sensors were first cleaned by UV irradiation in a UV-ozone chamber for $10 \mathrm{~min}$, followed by immersion in a mixture of 5:1:1 distilled water/hydrogen peroxide/ammonium hydroxide for 30 min in an ultrasound bath at $70^{\circ} \mathrm{C}$. After thorough rinsing with distilled water, the surfaces were once again irradiated by UV light. After this treatment, the surfaces were modified with alkanethiol compounds relying on gold-sulfur bonds to generate four distinct surfaces with controlled chemistry, exhibiting the following functional groups: $\mathrm{CH}_{3}, \mathrm{OH}, \mathrm{COOH}$ and $\mathrm{NH}_{2}$. These groups are found respectively in 1-dodecanethiol, 11-mercapto-1-undecanol, 12mercaptododecanoic acid, and 11-amino-1-undecanethiol hydrochloride. The procedure was based on well-known mechanisms of SAMs preparation of alkanethiols on gold. ${ }^{19,28-31}$ The clean gold surfaces were immersed in $3 \mathrm{~mL}$ of a $20 \mu \mathrm{M}$ ethanol solution of the desired alkanethiol compound. After $48 \mathrm{~h}$, the modified surfaces were rinsed with absolute ethanol, dried with a flow of nitrogen and placed in the sample chamber of either the QCM-D or MP-SPR to monitor the assembly of the ELRs on each SAM. 


\section{Quartz-crystal microbalance with dissipation monitoring. A Q-Sense E4 quartz crystal}

microbalance (Biolin Q-Sense, Sweden) with dissipation monitoring system was used to follow the adsorption of V84-ELR and EI-ELR coatings on alkanethiol-modified gold-coated quartz crystals in real time. The quartz crystal was excited at multiple overtones $(1,3,5,7,9,11$, and 13, corresponding to $5,15,25,35,45,55$, and $65 \mathrm{MHz}$, respectively). Depositions of mass were detected by variations in the normalized frequency $\left(\Delta f_{n} / n\right)$ and viscoelasticity by variations in dissipation $\left(\Delta D_{n}\right)$, where $n$ is the overtone number. A stable baseline $\left(\Delta f_{n} / n<1 \mathrm{~Hz}\right.$ in $\left.10 \mathrm{~min}\right)$ was acquired with PBS before starting the assembly of ELRs. Adsorption took place at $25{ }^{\circ} \mathrm{C}$, using $100 \mu \mathrm{g} \cdot \mathrm{mL}^{-1}$ ELR solutions in PBS, and at a constant flow rate of $50 \mu \mathrm{L} \cdot \mathrm{min}^{-1}$. ELRs were flushed for at least $1 \mathrm{~h}$ and until adsorption reached an equilibrium (variation of $\Delta f_{n} / n<5 \%$ during a period of $30 \mathrm{~min}$ ), followed by a rinsing step of $1 \mathrm{~h}$ to remove loosely bonded molecules.

The thickness of each polypeptide coating was estimated using the Voigt-based viscoelastic model, adequate for soft and hydrated polymeric superficial assemblies, contained in the QTools software from Q-Sense (version 3.1.25.604). The model is based on Equation 1 and 2,

$$
\begin{aligned}
& \Delta F \approx-\frac{1}{2 \pi \rho_{0} h_{0}}\left\{\frac{\eta_{3}}{\delta_{3}}+\sum_{j=k}\left[h_{j} \rho_{j} \omega-2 h_{j}\left(\frac{\eta_{3}}{\delta_{3}}\right)^{2} \frac{\eta_{j} \omega^{2}}{\mu_{j}^{2}+\omega^{2} \eta_{j}^{2}}\right]\right\} \\
& \Delta D \approx \frac{1}{2 \pi f \rho_{0} h_{0}}\left\{\frac{\eta_{3}}{\delta_{3}}+\sum_{j=k}\left[2 h_{j}\left(\frac{\eta_{3}}{\delta_{3}}\right)^{2} \frac{\mu_{j} \omega}{\mu_{j}^{2}+\omega^{2} \eta_{j}^{2}}\right]\right\}
\end{aligned}
$$

where considering a total of $k$ thin viscoelastic layers, $\rho_{0}$ and $h_{0}$ are the density and thickness of the quartz crystal, $\eta_{3}$ is the viscosity of the bulk liquid, $\delta_{3}$ is the viscous penetration depth of the shear wave in the bulk liquid, $\rho_{3}$ is the density of liquid, $\mu$ is the elastic shear modulus of an overlayer, and $\omega$ is the angular frequency of the oscillation. ${ }^{32}$ Iterations of the model were performed using at least three overtones, fixing the values of solvent density, solvent viscosity, 
and film density in $0.001 \mathrm{~Pa} . \mathrm{s}$ (same as water) and the film density at $1200 \mathrm{~kg} \cdot \mathrm{m}^{-3}$ (often assumed to return the lowest calculation error). ${ }^{33-35}$ The solvent density was varied by trial and error between 1000 and $1060 \mathrm{~kg} \cdot \mathrm{m}^{-3}$ until the lowest value of the total error, $\chi^{2}$, was found. The estimated values represent the hydrated thickness of the assembled coatings, $T h_{Q C M-D}$. Additional estimations were made using the Sauerbrey model which assumes a purely rigid behavior, following Equation 3,

$$
\Delta m=-\frac{C \times \Delta f}{n}
$$

where $\Delta m$ is the Sauerbrey areal mass, $C$ is the mass sensitivity constant $\left(17.7 \mathrm{ng} \cdot \mathrm{cm}^{-2} \cdot \mathrm{s}\right)$, and $n$ is the overtone number. ${ }^{36}$

Multi-parametric surface plasmon resonance. The assembly of ELR coatings on each SAM was followed by monitoring optical variations at the surface of MP-SPR gold-coated sensors using a multi-parametric instrument, model SPR Navi200 (BioNavis, Finland). Full angle scans were performed simultaneously at $670 \mathrm{~nm}$ and $785 \mathrm{~nm}$ and monitored in real time throughout the following steps. First, clean surfaces were analyzed in air to assess the cleanness of the surface, followed by the flow of $100 \mu \mathrm{g} \cdot \mathrm{mL}^{-1}$ ELR solution in PBS at $50 \mu \mathrm{L} \cdot \mathrm{min}^{-1}$. Variations of mass are detected by MP-SPR dip angle shifts registered in sensograms, using the wide angular scan range $\left(40^{\circ}-78^{\circ}\right)$. The monitoring times adopted for the MP-SPR measurements were replicated from the QCM-D experiments. After monitoring the adsorption and rinsing, the surfaces were dried. For that, they were immediately rinsed with distilled water to remove excess of PBS salts, which present high refractive index when dry. Then, drying was performed in situ, i.e., without removing the surfaces from the MP-SPR sample chamber, to ensure that the coatings retained internal integrity, by pumping air until the reflection angle dropped to typical reflection values in air $\left(\sim 40^{\circ}\right)$. The optical thickness of each ELR adsorbed onto each SAM was estimated by 
following a two-color MP-SPR approach combined with two media measurements for the simultaneous and unambiguous determination of the thickness of ELR coatings ${ }^{22,23}$ Briefly, this approach requires the analysis of reflective curves both at $670 \mathrm{~nm}$ and $785 \mathrm{~nm}$ in air and liquid, using as inputs the curves of (i) the bare surface in air, prior to the start of the ELR flow, (ii) the surface hosting the ELR by the end of the assembly in liquid, and (iii) the dry coating in air. Winspall (version 3.02, Max Planck Institute for Polymer Research, Germany) was used for the simulation of reflectivity curves based on the Fresnel formalism, described by Equations 4 to 7 ,

$$
\begin{aligned}
& r_{s}=\frac{n_{1} \cos \theta_{i}-n_{2} \cos \theta_{t}}{n_{1} \cos \theta_{i}+n_{2} \cos \theta_{t}} \\
& t_{s}=\frac{2 n_{1} \cos \theta_{i}}{n_{1} \cos \theta_{i}+n_{2} \cos \theta_{t}} \\
& r_{p}=\frac{n_{2} \cos \theta_{i}-n_{1} \cos \theta_{t}}{n_{1} \cos \theta_{t}+n_{2} \cos \theta_{i}} \\
& t_{p}=\frac{2 n_{1} \cos \theta_{i}}{n_{1} \cos \theta_{t}+n_{2} \cos \theta_{i}}
\end{aligned}
$$

where, for s- and p- light polarizations, $r$ and $t$ respectively stand for reflected and transmitted electric field, $n_{1}$ and $n_{2}$ represent the refractive indexes of the media light moves from and to, and $\theta_{i}$ and $\theta_{t}$ are the angles that the incident and refracted rays make to the normal of the interface. The estimated values are equivalent to the dehydrated thickness of the assembled polypeptide coatings, $T h_{M P-S P R}$.

Hydration of the polypeptide coatings. The hydration $(H d)$ of each coating was determined by Equation 8,

$$
H d(\%)=\frac{T h_{Q C M-D}-T h_{M P-S P R}}{T h_{Q C M-D}} \times 100
$$

where $T h_{Q C M-D}$ and $T h_{M P-S P R}$ are the thickness values estimated from the QCM-D and MP-SPR data, respectively. 
Atomic force microscopy measurements. For the visualization of ELR aggregates, a $50 \mu \mathrm{L}$ droplet of a $100 \mu \mathrm{g} \cdot \mathrm{mL}^{-1}$ ELR in PBS stabilized at $25^{\circ} \mathrm{C}$ was pipetted on mica, followed by drying overnight at room temperature to allow the aggregates' fixation on mica. After drying, the surfaces were gently dipped in distilled water three times to remove excess of salt crystals formed as a result of the drying and the remaining water was removed with the aid of a nitrogen flow. For the visualization of the thinnest and the thickest V84-ELR and EI-ELR coatings (determined after calculating $T h_{Q C M-D}$ and $T h_{M P-S P R}$ ), they were assembled onto gold-coated quartz sensors during a normal operation of the QCM-D, at a constant flow of $50 \mu \mathrm{L} \cdot \mathrm{min}^{-1}$. The sensors were retrieved, rinsed with distilled water and left to dry overnight at room temperature. The visualization of both samples was performed in air at room temperature using a NanoWizard 3 BioAFM (JPK Instruments AG, Germany) under AC mode, using ACSTA cantilevers. Topography images were recorded with a resolution of $512 \times 512$ data points, using a line rate of $1 \mathrm{~Hz}$ and a relative setpoint of $\sim 90 \%$ of the free oscillation of the cantilever. Image analysis was performed on uncoated and coated with EI-ELR OH-terminated surfaces using ImageJ (version 1.52a) with the function "Plot Profile".

Statistical analysis. Size, polydispersion, $\Delta f_{7} / 7, \Delta D_{7}$, and $T h_{Q C M-D}$ values reported are means \pm one standard deviation (SD) of three independent experiments. The maximum standard error of $T h_{M P-S P R}$ was determined based on three independent experiments of EI-ELR adsorption on OHterminated surfaces, the condition representing the thinnest of the coatings. Statistical significance between $T h_{Q C M-D}$ values was analyzed using a two-way ANOVA statistical analysis in Microsoft Excel 2013 (Microsoft, USA). All results were considered to be statistically significant at a $p$-value less than $0.05(*), 0.01(* *)$, and $0.001(* * *)$. 


\section{RESULTS AND DISCUSSION}

In order to determine how the structure of proteins can affect the stiffness of a surface upon adsorption, we used two custom-made ELRs with different sequences and organized in blocks, as represented in Figure 1.

(A)

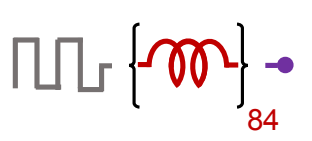
MGKKKP(VPGVG) ${ }_{84} \mathrm{~V}$
(B)

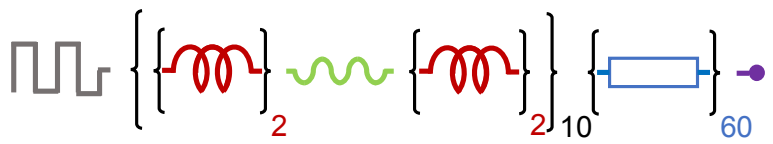

MGKKKP [(VPGVG) $\left.{ }_{2}(\mathrm{VPGEG})(\mathrm{VPGVG})_{2}\right]_{10}(\mathrm{VGIPG})_{60} \mathrm{~V}$

(C)
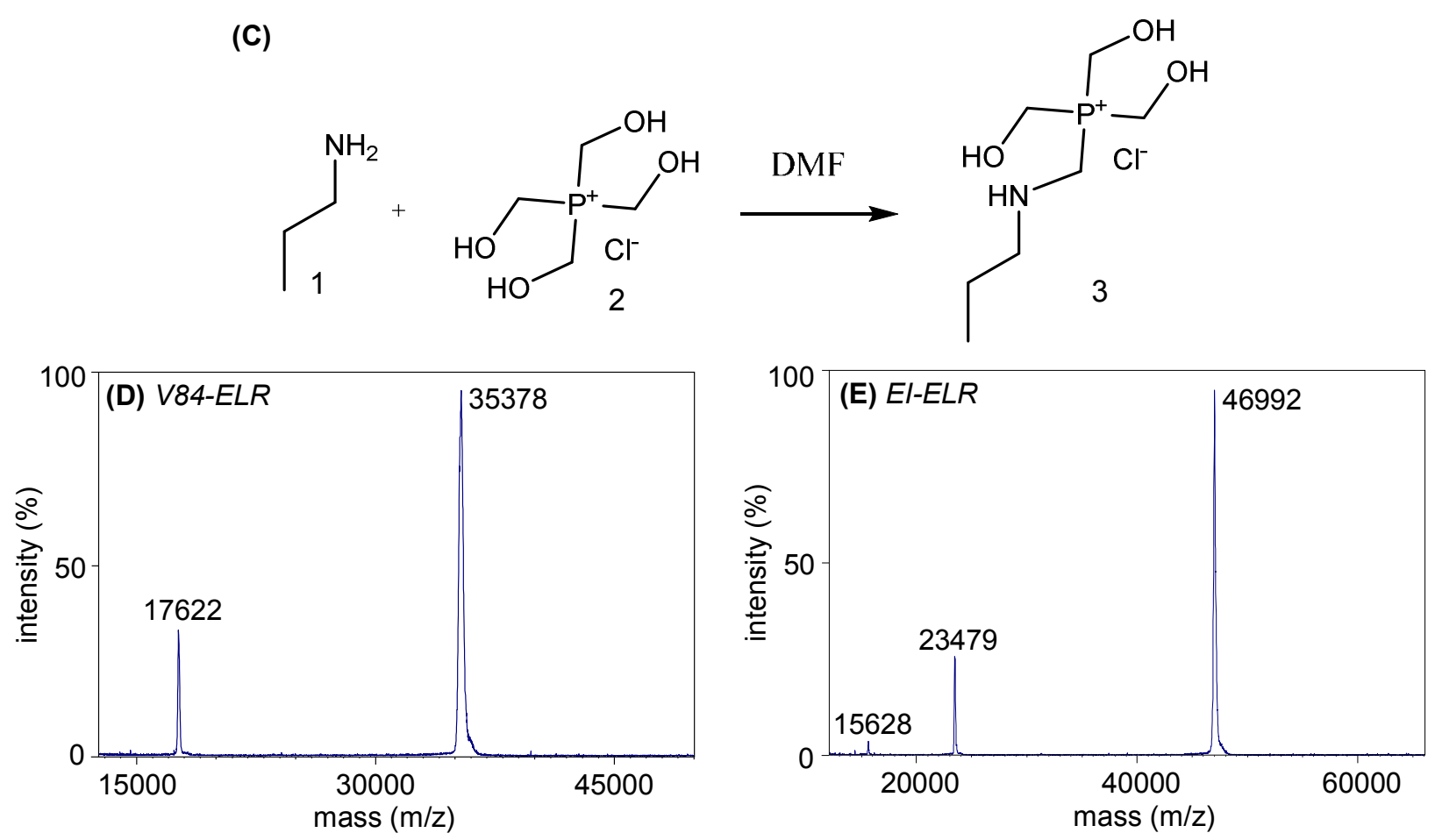

Figure 1. Schematic representation of the predicted amino acid sequences of unmodified versions of (A) V84-ELR and (B) EI-ELR. (C) Reaction scheme of the modification of ELRs with THPC, with 1 representing unmodified ELRs, 2 representing THPC and $\mathbf{3}$ the modified product. (D, E) MALDI-TOF spectra of modified ELRs. Major molecular weight peaks were detected at $35378 \mathrm{Da}$ and $46992 \mathrm{kDa}$, respectively. 
The first one, unmodified V84-ELR, is a hydrophobic monoblock (Figure 1A) constituted by 84 repetitive elastin pentapeptide sequences of $\mathrm{VPG} X \mathrm{G}$, in which $X$ is valine (V). The second ELR, unmodified EI-ELR, is an amphiphilic diblock (Figure 1B). Each block consisted of variations of the VPGXG pentapeptide, with one being a hydrophilic block with 10 glutamic acids (E) and the other being a hydrophobic block with 60 isoleucines (I). Amino acid quantification assays matched well the theoretical composition of both ELRs (Table S1), point toward the production of ELRs with the expected amino acid sequence and monoblock or diblock architectures. Afterwards, the as-received ELRs were modified with THPC according to the reaction in Figure 1C. Of note, the studied ELRs have similar molecular weight to eliminate the influence of this property in the following experiments. ${ }^{37}$ The spectra obtained by MALDITOF confirmed the molecular weight of both ELRs (Figures 1D and 1E), as their molecular weights match after the introduction of one THPC molecule per ELR chain.

The construction of ELR-based films requires that both V84-ELR and EI-ELR are used in their non-precipitated form, i.e., below $T_{t}$. In order to determine the $T_{t}$ of each ELR, we determined the hydrodynamic aggregate size and their polydispersity index (PDI, as related to the nonuniformity of the diameter distribution) in phosphate buffered saline ( $\mathrm{PBS}, \mathrm{pH}=7.4)$ as a function of the temperature (Figure 2). A sudden increase of the hydrodynamic aggregate size is indicative of the hydrophobic association of ELR free chains into increasingly larger particles, leading to the typical ITT phase-separation. Macroscopically, this transition is accompanied by an increase in turbidity and occurs when $T_{t}$ is reached. The hydrodynamic size of V84-ELR increased greatly from $553 \mathrm{~nm}$ to $1928 \mathrm{~nm}$ around $32^{\circ} \mathrm{C}$, showing that this is the $T_{t}$ of this ELR (Figure 2A). A decrease of the PDI was also observed (from 0.7 to 0.2 ), indicating a more homogeneous size distribution above $T_{t}$. The low PDI above $T_{t}$ is consistent with the folding of 
ELR chains into dynamic, regular, non-random $\beta$-spiral structures, associated with a transition to a higher ordered state as a result of an increment of the temperature.
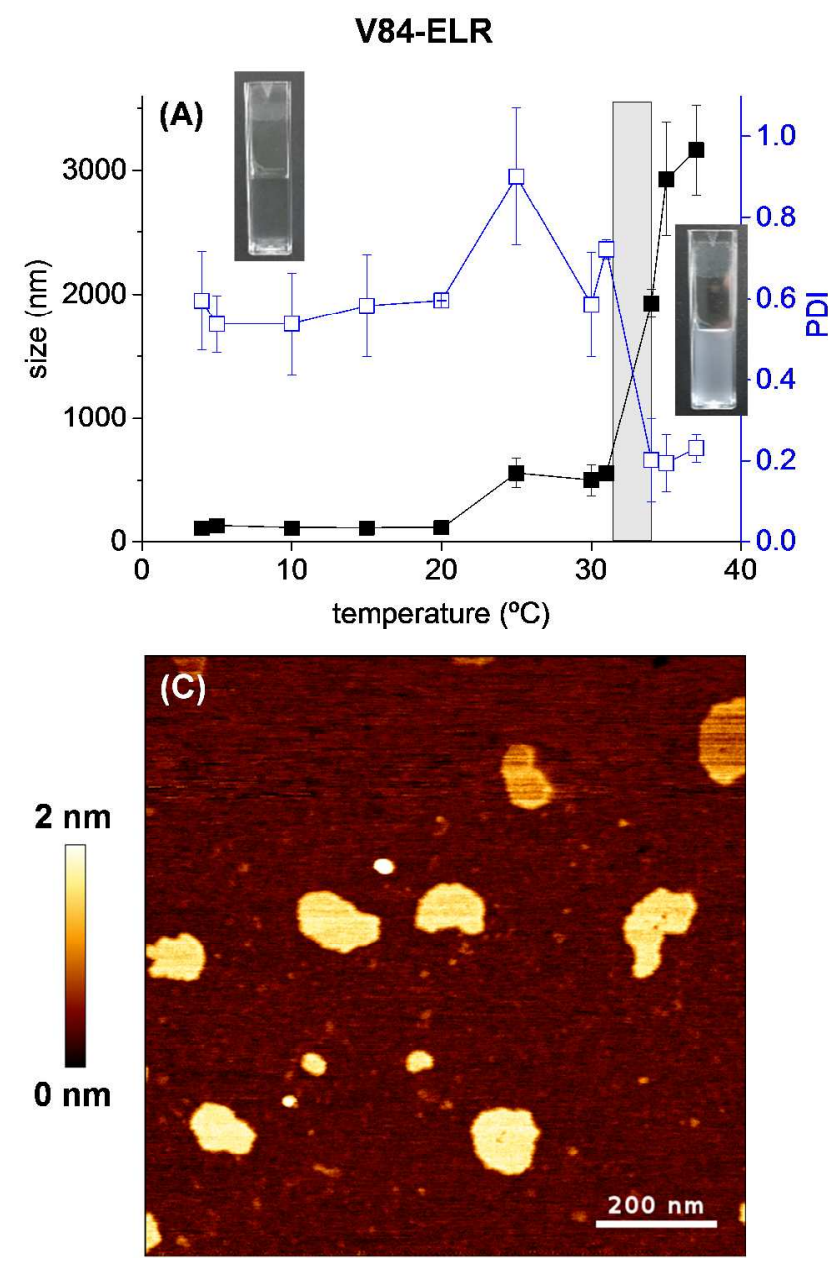

EI-ELR
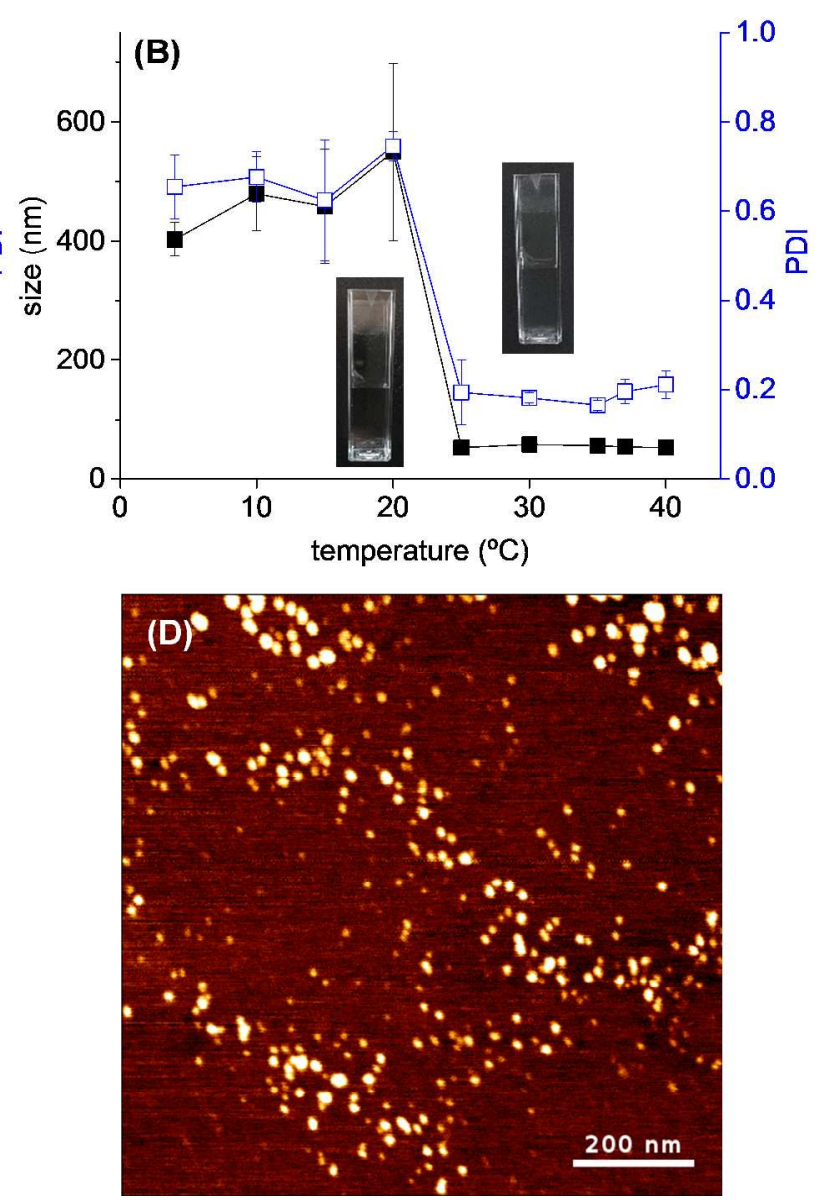

Figure 2. Hydrodynamic size profile in terms of diameter ( $\mathbf{a})$ and polydispersity index (PDI, $\square$ ) for $100 \mu \mathrm{g} \cdot \mathrm{mL}^{-1}$ solutions of (A) V84-ELR and (B) EI-ELR, in PBS within a temperature range of $4-40^{\circ} \mathrm{C}$. Data are presented as means \pm standard deviation. The lines are drawn for visual guidance only. The inset photographs show the macroscopic aspects of non-precipitated (clear) and precipitated ELRs (cloudy white). AFM imaging (AC mode) of (C) V84-ELR and (D) EIELR, carried out in air at room temperature. Scale bar: $200 \mathrm{~nm}$. 
Below $T_{t}$, ELR chains behave as disordered random coils, which translates into higher PDI values. ${ }^{38}$ The polydisperse character of V84-ELR aggregates below $T_{t}$ was confirmed by AFM (Figure 2C), revealing aggregates with undefined shape and varying dimensions (up to $60 \mathrm{~nm}$, at dry conditions). The behavior of V84-ELR with temperature variations was thus typical of ELRs in aqueous solutions.

The amphiphilic diblock EI-ELR behaved differently (Figure 2B). From $20{ }^{\circ} \mathrm{C}$ to $25^{\circ} \mathrm{C}$, the hydrodynamic aggregate size decreased from $549 \mathrm{~nm}$ to $54 \mathrm{~nm}$ and became more homogeneous (PDI decreased from 0.7 to 0.2 ). The photograph insets in Figure 2B showed that the solution retained a clear aspect. This behavior is not consistent with the typical trend observed for ELRs. We hypothesize that the hydrodynamic size decrease was not related to the molecular dynamics of ELR folding and coacervation, since a change in turbidity would accompany this phenomenon. In fact, this behavior resembles the formation of ELR vesicles with micelle-like properties. Garcia et al previously demonstrated that diblock $\mathrm{E}_{50} \mathrm{I}_{60}$ ELRs self-assemble into spherical vesicles with hydrodynamic diameter similar to the one measured by us $(\approx 50 \mathrm{~nm}) .{ }^{39}$ Further increase of the temperature above $25^{\circ} \mathrm{C}$ did not result in any additional changes in hydrodynamic size, PDI, or turbidity, suggesting that the $T_{t}$ of EI-ELR must be higher than $40{ }^{\circ} \mathrm{C}$ (the upper limit of the experimental temperature range). Figure S1 shows that for higher concentrations (i.e., $50 \mathrm{mg} \cdot \mathrm{mL}^{-1}$ ) EI-ELR has a transition around $12{ }^{\circ} \mathrm{C}$. The higher concentration of that sample - a factor that contributes to lowering the $T_{t}$ of $\operatorname{ELPs}^{40}-$ explains why a transition was not observed for the lower concentration used herein to assemble our coatings. The insertion of the hydrophilic block in the structure of EI-ELR contributed to the increase of polarity, resulting in a higher $T_{t}$ in respect to V84-ELR. This is consistent with the fact that more polar ELRs have higher $T_{t}{ }^{41}$ 
To confirm the formation of EI-ELR aggregates above $20^{\circ} \mathrm{C}$, AFM measurements were made (Figure 2D). The results show that EI-ELR forms nanoaggregates, with approximately $20 \mathrm{~nm}$ in dry conditions, which is in agreement with the previous findings for $\mathrm{E}_{50} \mathrm{I}_{60}$. These measurements were made in the dry state. On the one hand, the drying step is needed to immobilize the ELRs on the mica, but on the other hand, one should be aware that the increasing ELR concentration during the slow drying process can induce different conformational changes and/or aggregation. Altogether these results showcase that block ELRs with well-defined hydrophilic and hydrophobic regions generate polypeptides with significantly different thermal responses and molecular arrangements. From this point forward, the assembly of ELR coatings was conducted at $25^{\circ} \mathrm{C}$, to operate below the $T_{t}$ of V84-ELR and above the temperature at which EI-ELR forms monodisperse nanoaggreagates.

If ELRs are to be model protein-based building blocks for the assembly of films with tunable rigidity, it is necessary to understand how they interact with substrates exhibiting diverse surface chemistries. For this purpose, QCM-D and MP-SPR gold sensors were first modified with alkanethiols with different head groups. We used four SAMs: $\mathrm{CH}_{3}$ (as model for hydrophobic, non-polar surface), $\mathrm{OH}$ (model for uncharged but polar surface), $\mathrm{COOH}$ (polar, charged negatively) and $\mathrm{NH}_{2}$ (polar, charged positively), covering a broad set of surfaces with different chemistries. QCM-D and MP-SPR assays allow estimation of the thickness of ELR coatings in their hydrated and dehydrated states $\left(T h_{Q C M-D}\right.$ and $T h_{M P-S P R}$, respectively). After estimating $T h_{Q C M-D}$ and $T h_{M P-S P R}$, one can determine not only the binding affinity of each ELR to the underlying SAM of the ELRs but also the hydration of the coatings and their dissipative behavior (i.e., if it is soft or rigid). 
QCM-D is based on acoustic piezoelectric principle, which is sensitive to shear viscosity and hydration. It is, therefore, a suitable approach to analyze the assembly and physicochemical properties of hydrated films. Figure 3 shows the frequency $\left(\Delta f_{7} / 7\right.$, Figures $3 \mathbf{A}$ and $\left.3 \mathbf{B}\right)$ and dissipation $\left(\triangle D_{7}\right.$, Figures $3 \mathrm{C}$ and 3D) variations, normalized to the $7^{\text {th }}$ overtone for the studied ELRs adsorbed on each surface. Additional overtones are represented in Figures S2 and S3.
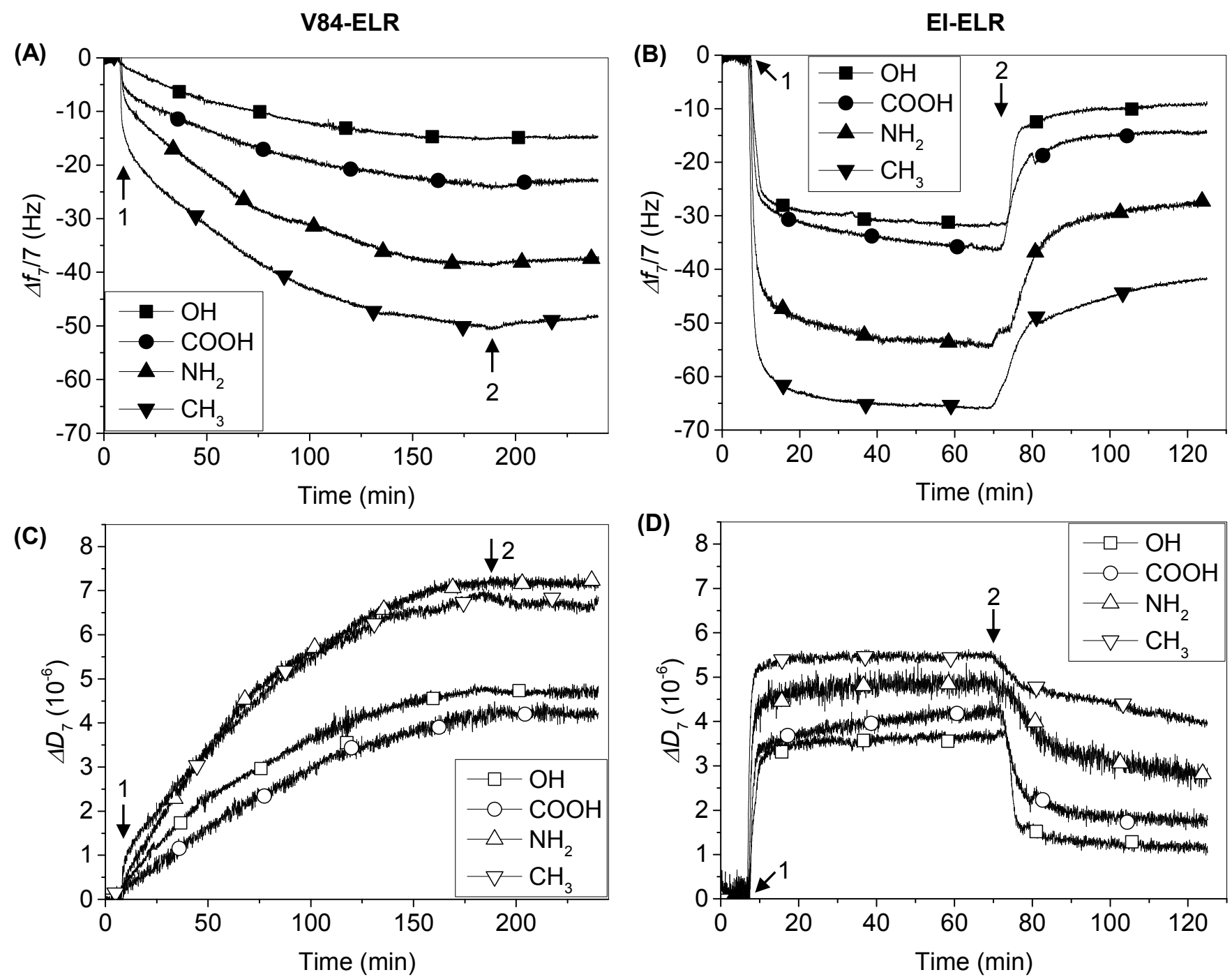

Figure 3. Representative QCM-D data for frequency ( $\triangle f$, $\mathrm{A}$ and $\mathrm{B})$ and dissipation $(\triangle D, \mathrm{C}$ and D) variations normalized to the $7^{\text {th }}$ harmonic $(35 \mathrm{MHz})$ during the deposition of V84-ELR $(\mathrm{A}, \mathrm{C})$ and EI-ELR (B, D) on gold-coated quartz sensors functionalized with $\mathrm{OH}$ (squares), $\mathrm{COOH}$ 
(circles), $\mathrm{NH}_{2}$ (triangles), and $\mathrm{CH}_{3}$ (inverted triangles) $\mathrm{SAMs}$. The arrows indicate (1) ELR injection and (2) rinsing step.

We observed ELRs adsorption at all studied conditions: the decrease in the $\Delta f_{7} / 7$ signal indicated that both V84-ELR (Figure 3A) and EI-ELR (Figure 3B) deposited on the SAMs. Both ELRs showed higher $\Delta f_{7} / 7$ on $\mathrm{NH}_{2}$ and $\mathrm{CH}_{3} \mathrm{SAMs}$, but the profile of the adsorption process is different for the ELRs. At first glance, one can identify significant differences in the saturation frequency, adsorption time, and dissipation variations. First, it is clear that V84-ELR has a higher affinity to the underlying SAMs than EI-ELR. For example, on $\mathrm{CH}_{3}$-terminated surfaces (i.e., the surfaces for which we registered the highest frequency variations), $\Delta f_{7} / 7$ reached about $-46.5 \mathrm{~Hz}$ and $-40.6 \mathrm{~Hz}$ for V84-ELR and EI-ELR, respectively, after rinsing. This tendency was observed on all underlying SAMs. Furthermore, mass loss is visible for EI-ELR coatings during the rinsing step, indicating loosely bonded material that is washed out from the surface. Such mass loss does not occur with V84-ELR, showing that this monoblock ELR has higher affinity to the underlying SAMs. Possible explanations may reside in the complex behavior of dynamic objects such as proteins (e.g., different conformations, folding and exposition of binding sites as well as aggregation/disaggregation) as compared with inert and/or stable nano-objects, ${ }^{42}$ and in the adsorption mechanism of fibrillar - such as elastins - and globular proteins. ${ }^{21}$ During the initial contact with the surface, fibrillar proteins adhere in a conformation parallel to the substrate, maximizing the polypeptide/surface interaction area. A micelle-like structure, on the other hand, is more likely to interact with the surface through a single region of its configuration (in the case of EI-ELR, just one of its blocks), ${ }^{43}$ thus resulting in a weaker binding affinity.

The second main difference is the adsorption time. An initial sharp decrease of $\Delta f_{7} / 7$ is observed for EI-ELR (Figure 3B), while steady process is visible in the case of V84-ELR. 
Moreover, the adsorption of V84-ELR reaches an equilibrium within about $3 \mathrm{~h}$ while EI-ELR needs shorter period (about $1 \mathrm{~h}$ ) to reach this state. These results show that polypeptides built from multiples blocks adsorb faster than those with a single block, suggesting that EI-ELR adsorption is kinetically driven. On the other hand, no removal of the slowly deposited V84-ELR is observed during the rinsing step, alluding to a thermodynamic controlled adsorption. ${ }^{44}$

There was also a pronounced difference in the dissipative character of the coatings, revealed by the increasing values of $\Delta D_{7}$ with time (Figure 3C and Figure 3D). The dissipation is associated with the deposition of soft components and coupling of water which often lead to a loss of energy from the sensor's oscillation. The obtained $\Delta D_{7}$ data reveal viscoelastic behavior for the adsorbed ELRs. For example, on $\mathrm{CH}_{3}$-terminated SAMs, $\Delta D_{7}$ after rinsing was $6.6 \times 10^{-6}$ and $4.0 \times 10^{-6}$, for V84-ELR and EI-ELR, respectively. Surprisingly, we measured higher $\Delta D_{7}$ for V84-ELR as compared with EI-ELR indicating higher hydration for the monoblock polypeptide. It was expected that more water molecules would couple with EI-ELR, due to its hydrophilic block. This seeming contradiction can be explained by the different hydration mechanisms for polar and nonpolar moieties. Nonpolar amino acids present in ELRs are hydrated by hydrophobic hydration, which involves ordered clathrate-like water structures around such residues. ${ }^{41}$ Previous calorimetry assays with ELPs showed endothermic component due to the loss of water molecules involved in hydrophobic hydration. ${ }^{45}$ The lower polarity of ELPs is related with higher magnitude of the endothermic component, and thus the higher the number of water molecules coupled by hydrophobic hydration. This phenomenon explains the higher dissipative behavior of V84-ELR coatings, which surpasses the hydration of the EI-ELR diblock structure. MP-SPR characterization was used to complement these results. We used a multi-parametric equipment operating with lasers at two wavelengths: $670 \mathrm{~nm}$ and $785 \mathrm{~nm}$. In this technique, the 
resonance angle resulting from the reflection of the lasers increases when mass deposits on a surface. Optical shifts are nearly unaffected by coupled water, which provide an approximation proportional to the adsorbed dehydrated mass. Although the refractive index of distinct layers vary with hydration, these variations are often neglected in the calculations of the Fresnel formalism. Similarly to QCM-D, MP-SPR assays monitored the adsorption of V84-ELR and EIELR in real time on each of the alkanethiol-terminated gold surfaces. Representative reflective curves in PBS are shown for V84-ELR (Figure 4A) and EI-ELR (Figure 4B).
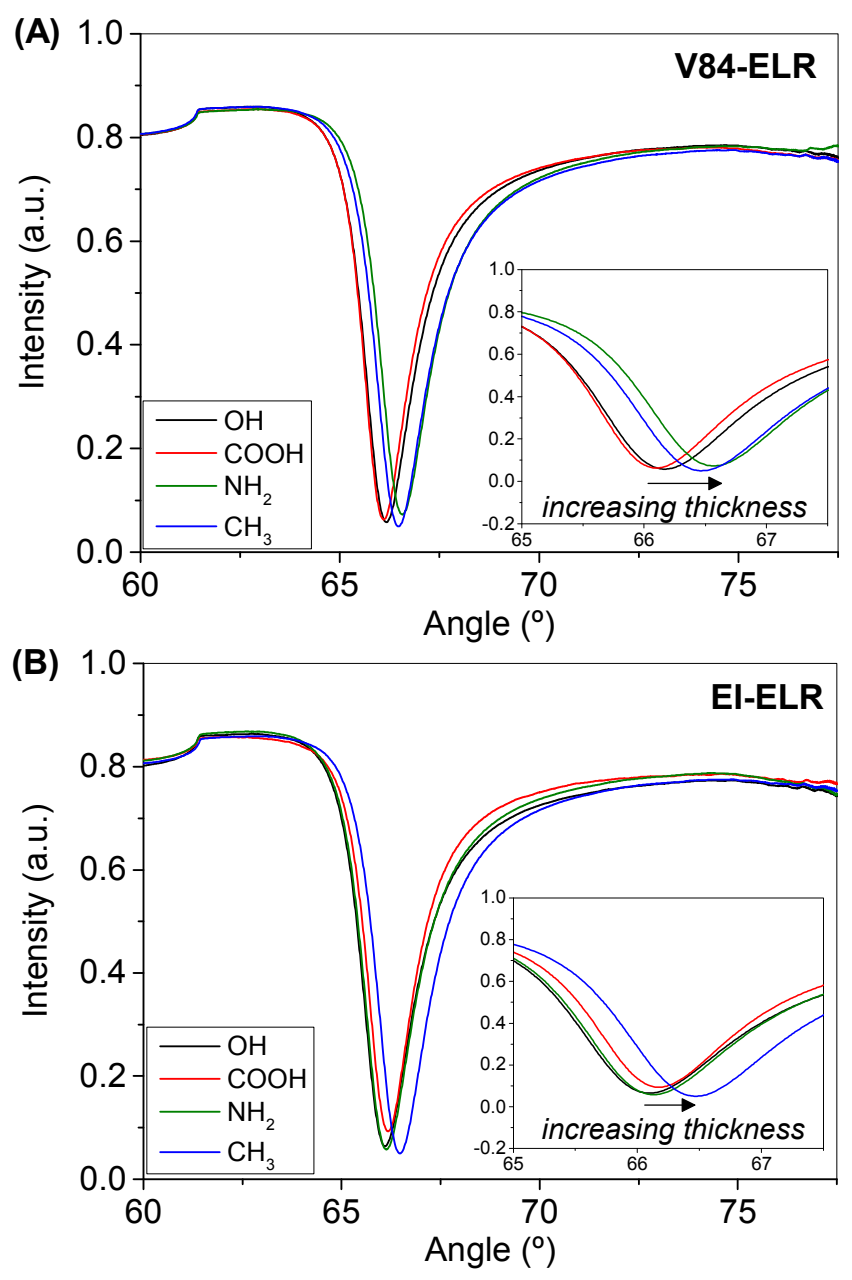
Figure 4. Representative reflectivity curves (MP-SPR curves) of the adsorption of (A) V84-ELR and (B) EI-ELR on self-assembled monolayers terminated in $\mathrm{OH}$ (black), $\mathrm{COOH}$ (red), $\mathrm{NH}_{2}$ (green) and $\mathrm{CH}_{3}$ (blue). Data acquired at wavelength $785 \mathrm{~nm}$ in PBS is shown.

The minimum intensity peaks (which represent the maximum angle of absorption) were found within a tight range, between $66^{\circ}$ and $67^{\circ}$, suggesting the adsorption of thin nanocoatings of ELRs on each surface. For V84-ELR coatings (Figure 4A), the resonance angle of the peaks varied between $66.1^{\circ}$ and $66.6^{\circ}$ on $\mathrm{COOH}$ and $\mathrm{NH}_{2}$ SAMs, respectively. For EI-ELR coatings (Figure 4B), the values varied between $66.1^{\circ}$ and $66.5^{\circ}$, on $\mathrm{OH}$ and $\mathrm{CH}_{3} \mathrm{SAMs}$, respectively. In accordance with the QCM-D data, the MP-SPR results showed a preferential affinity of both ELRs for $\mathrm{NH}_{2}$ and $\mathrm{CH}_{3}$ SAMs (green and blue curves in the graphs of Figure 4).

An accurate measure of such affinity requires the calculation of $T h_{M P-S P R}$. In order to determine the dehydrated thickness of the coatings, an additional monitoring stage was performed to obtain their reflectivity curves in the dry state. The wide angular scan range $\left(40^{\circ}-78^{\circ}\right)$ of the used equipment and the sharp differences in the position of the resonance angle in air or in water allow measurements in these two media without taking the sensor out of the instrument. The analysis of these conditions following the Fresnel formalism (Equations 4 to 7) allowed to calculate $T h_{M P-S P R}$, which are presented in Table 1.

Table 1. Maximum (saturation) frequency and dissipation variations and the respective Voigt thickness, $T h_{Q C M-D}$, for the V84-ELR and EI-ELR adsorption on different thiol-terminated surfaces $\left(7^{\text {th }}\right.$ overtone). Optic thickness, $T h_{M P-S P R}$, determined by the two-wavelength and twomedia MP-SPR approach. 


\section{V84-ELR}

\begin{tabular}{cccccc}
\hline Surface & $\begin{array}{c}\text { Saturation } \Delta f_{7} / 7 \\
(\mathrm{~Hz})\end{array}$ & $\begin{array}{c}\text { Saturation } \Delta D_{7} \\
\left(10^{-6}\right)\end{array}$ & $T h_{Q C M-D}(\mathrm{~nm})^{\mathrm{a}}$ & $T h_{M P-S P R}(\mathrm{~nm})^{\mathrm{b}}$ & $H d(\%)^{\mathrm{c}}$ \\
\hline $\mathrm{OH}$ & $-17.9 \pm 2.9$ & $4.0 \pm 1.6$ & $3.7 \pm 2.0$ & 1.4 & 62 \\
$\mathrm{COOH}$ & $-23.3 \pm 3.0$ & $4.4 \pm 0.4$ & $5.2 \pm 1.0^{*}$ & 3.5 & 33 \\
$\mathrm{NH}_{2}$ & $-38.0 \pm 4.5$ & $7.3 \pm 0.6$ & $8.9 \pm 0.8^{* *}$ & 5.9 & 34 \\
$\mathrm{CH}_{3}$ & $-46.5 \pm 2.4$ & $6.6 \pm 0.4$ & $8.8 \pm 0.8$ & 6.0 & 32
\end{tabular}

\section{EI-ELR}

\begin{tabular}{cccccc}
\hline Surface & $\begin{array}{c}\text { Saturation } \Delta f_{7} / 7 \\
(\mathrm{~Hz})\end{array}$ & $\begin{array}{c}\text { Saturation } \Delta D_{7} \\
\left(10^{-6}\right)\end{array}$ & $T h_{Q C M-D}(\mathrm{~nm})^{\mathrm{a}}$ & $T h_{M P-S P R}(\mathrm{~nm})^{\mathrm{b}}$ & $H d(\%)$ \\
\hline $\mathrm{OH}$ & $-9.9 \pm 0.8$ & $0.7 \pm 0.9$ & $0.5 \pm 0.4$ & 0.4 & 20 \\
$\mathrm{COOH}$ & $-14.7 \pm 3.2$ & $1.6 \pm 0.3$ & $2.2 \pm 0.1^{*}$ & 1.8 & 18 \\
$\mathrm{NH}_{2}$ & $-24.9 \pm 3.3$ & $2.9 \pm 0.1$ & $4.8 \pm 1.0^{* *}$ & 3.8 & 21 \\
$\mathrm{CH}_{3}$ & $-40.6 \pm 1.8$ & $4.0 \pm 0.1$ & $7.4 \pm 1.3$ & 5.9 & 20
\end{tabular}

${ }^{\mathrm{a}} T h_{Q C M-D}$ of V84-ELR and EI-ELR coatings assembled on the same alkanethiol-terminated surface was statistically different for $* p<0.05$ and $* * p<0.01$. No statistical differences were found between coatings assembled on $\mathrm{OH}$ - and $\mathrm{CH}_{3}$-terminated surfaces $(p>0.05)$.

${ }^{\mathrm{b}} T h_{M P-S P R}$ has an estimated maximum standard error of $23 \%$.

${ }^{\mathrm{c}}$ The hydration, $H d$, was determined from the acoustic (QCM-D) and optic (MP-SPR) thickness using Equation 8.

$T h_{Q C M-D}$ was calculated according to the Voigt-based viscoelastic model, using the raw $\Delta f_{n} / n$ and $\Delta D_{n}$ of at least three harmonics. As for $T h_{M P-S P R}$, the reflectivity curves of both the "wet" and "dry" states of the coatings were used as input to the two-wavelength and two-media approach, based on the Fresnel formulas. The lowest $T h_{Q C M-D}$ was obtained for OH-terminated surfaces (V84-ELR: $3.7 \mathrm{~nm}$; EI-ELR: $0.5 \mathrm{~nm}$ ) whereas the thickest coatings were assembled on $\mathrm{CH}_{3}$ surfaces (V84-ELR: $8.8 \mathrm{~nm}$; EI-ELR: $7.4 \mathrm{~nm}$ ). In the case of V84-ELR, $T h_{Q C M-D}$ on $\mathrm{NH}_{2}$ and $\mathrm{CH}_{3}$ surfaces was nearly identical, suggesting a better thermodynamic affinity as compared to 
$\mathrm{OH}$ and $\mathrm{COOH}$. In the case of $T h_{M P-S P R}$, the same trend was observed: the thinnest coatings were obtained on $\mathrm{OH}$ (V84-ELR: $1.4 \mathrm{~nm}$; EI-ELR: $0.4 \mathrm{~nm}$ ) and the thickest on $\mathrm{CH}_{3}$ (V84-ELR: 6.0 nm; EI-ELR: $5.9 \mathrm{~nm})$.

These data demonstrated that ELR deposition depends on the substrate chemistry in the order: $\mathrm{OH}<\mathrm{COOH}<\mathrm{NH}_{2}<\mathrm{CH}_{3}$. On the polar uncharged $\mathrm{OH}$-terminated surfaces, ELRs may interact by weak hydrogen bonds, generating very thin coatings. Besides hydrogen bonds, the $\mathrm{COOH}-$ terminated surfaces (negatively charged) can also interact via electrostatic interactions (e.g. with the amine groups of the lysine (K) residues) and indeed, the determined $T h_{M P-S P R}$ and $T h_{Q C M-D}$ were slightly higher than for the $\mathrm{OH}$ functionalized substrates. The thickest coatings were obtained on SAMs that exhibit chemical complementarity with the ELRs. On $\mathrm{NH}_{2}$ (charged positively), the assembly was driven by the interaction of the phosphonium in the THPC salt with the amine groups. As for $\mathrm{CH}_{3}$ surfaces, the high affinity of ELRs to these groups was the result of the hydrophobic nature of the elastin pentapeptide. These can bind strongly to the surface via strong hydrophobic interactions, thus justifying the high $T h_{M P-S P R}$ and $T h_{Q C M-D}$ values. A closer look at the thickness also shows that V84-ELR coatings were thicker than EI-ELR ones assembled on all surfaces, which supports that the monoblock has a higher binding affinity than the diblock architecture, as previously discussed for $\Delta f_{7} / 7$ values (Figures $\mathbf{3 A}$ and $3 \mathbf{B}$ ).

$T h_{Q C M-D}$ and $T h_{M P-S P R}$ were further analyzed to calculate the hydration $(H d)$ of each polypeptide coating (Table 1). The $H d$ of V84-ELR varied between $32 \%$ and $34 \%$, except for the ones assembled on $\mathrm{OH}$, which exhibited a hydration of $62 \%$. Such a disparity reveals that the surface of this particular SAM-modified sensor was coupled with high amounts of water. It is possible that the low affinity of V84-ELR with OH groups favors the assembly water molecules surrounding the free ELR chains, which cannot cross the energetic barrier necessary to bind 
more strongly to the surface (Figure S4). In the case of EI-ELR coatings, $H d$ varied between $18 \%$ and $21 \%$. Comparing with V84-ELR, the hydration was lower for coatings made of this ELR, which is related to the less pronounced hydrophobic hydration effect discussed previously. This observation is consistent with the low $\Delta D_{7}$ values of EI-ELR coatings in respect to V84ELR (Figures 3C and 3D).

The higher dissipation and hydration of V84-ELR coatings have alluded to the softer behavior of these coatings and to the more rigid EI-ELR coatings. However, it is known that the underlying substrate chemistry directly imposes conformation and orientation shifts on proteinbased layers. ${ }^{46,47}$ In order to determine how the conformation and orientation of V84-ELR and EI-ELR evolve during deposition on alkanethiol-modified surfaces, the derivative of the frequency variations $\left(\Delta f_{7} / 7\right.$, from Figures $\mathbf{3 A}$ and $\left.\mathbf{3 B}\right)$ was calculated as a function of time, $d f_{7} / d t$. In Figure 5, the negative peaks correspond to periods of rapid adsorption, whereas positive peaks represent desorption of mass. The peak of rapid adsorption was reached within 2 to 3 min after the ELRs came in contact with the surface of the sensor (notice that the graph shows 5 min of baseline which does not contribute to this count), after which the adsorption rate gradually decreased. Our observations suggest that the events initiating the adsorption of ELRs on the surfaces were largely independent of the polypeptide architecture and chemistry of the underlying SAM. The existence of a time delay before the peak was reached resembles an adsorption mechanism that follows the generalized molecular kinetic model. ${ }^{48,49}$ This model predicts that the sudden presence of a surface induces a distance dependent chemical potential of proteins. According to this model, the ELR-surface interaction and the motion toward the surface would not be immediate and would depended on the time it takes for the macromolecules to diffuse towards the surface and the adoption of the optimal protein conformation. Nonetheless, 
some minor differences could be discerned between V84-ELR and EI-ELR behavior, considering that the latter ELR exhibits a micelle-like conformation in solution. Namely, the adsorption rate of EI-ELR decreased back to nearly 0 after 3 to 4 min after the adsorption peak, whereas V84ELR kept adsorbing with a lower rate for $2 \mathrm{~h}$. The intensity of the peaks was also different, with V84-ELR reaching a $d f_{7} / d t$ absolute value of about 5 and EI-ELR about 30 (for $\mathrm{CH}_{3}$-terminated surfaces). These observations confirm the faster adsorption of the latter, and that the diblock organization facilitates the establishment of a bond with the surface, even if it is a weak bond. In fact, the positive peaks seen for EI-ELR around $70 \mathrm{~min}$ correspond to the rinsing stage and removal of loosely bonded molecules, due to the lower surface affinity.
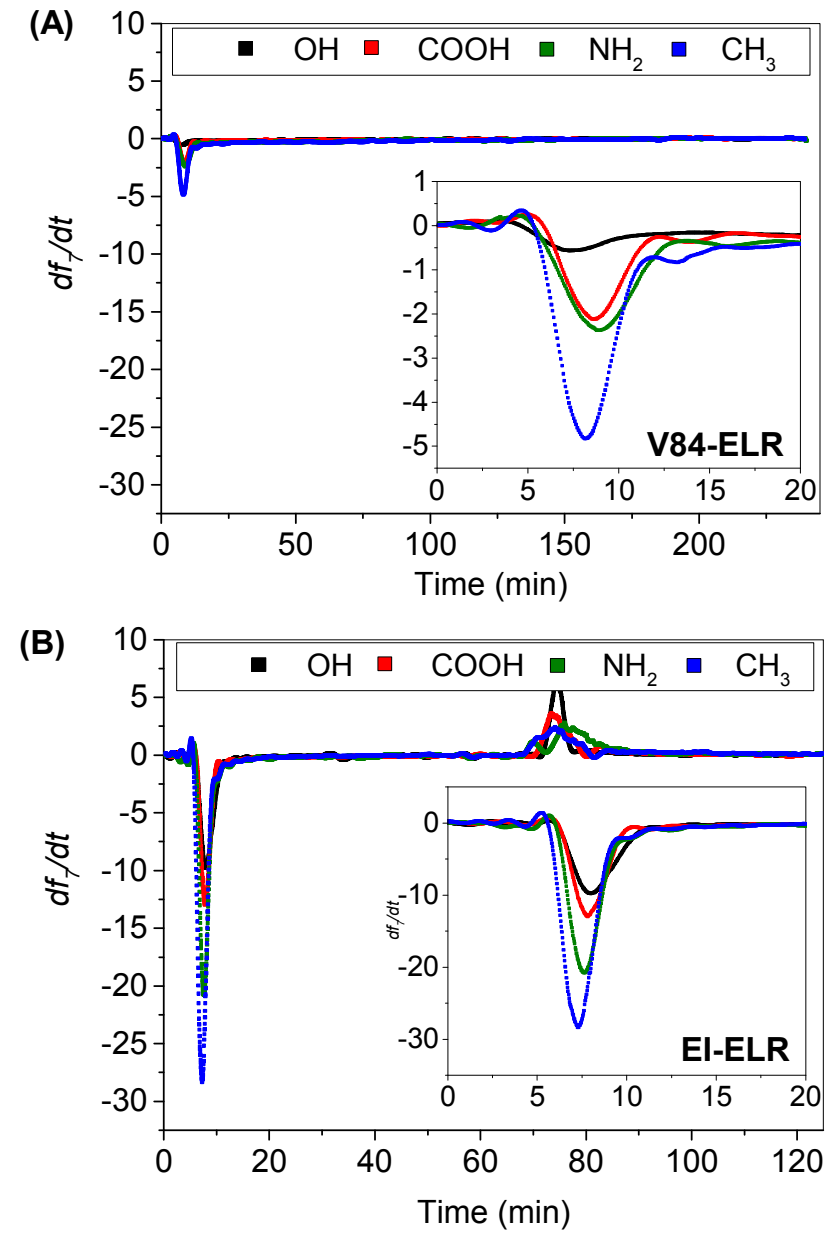
Figure 5. Derivatives of the variations of frequency normalized to the $7^{\text {th }}$ harmonic $\left(d f_{7} / d t\right)$ for (A) V84-ELR and (B) EI-ELR, assembled on $\mathrm{OH}$ (black), $\mathrm{COOH}$ (red), $\mathrm{NH}_{2}$ (green) and $\mathrm{CH}_{3}$ (blue) terminated surfaces as a function of time. The derivatives were calculated from the initial $\Delta f_{7} / 7$ adsorption profiles plotted in Figure 3. Insets are zoomed in values for the first 20 min of assay, including 5 min of baseline at the beginning.

We previously studied the layer-by-layer assembly of several variations of ELRs with polysaccharides in the QCM-D, but the issues of conformation, reorganization and mechanical properties were not addressed. ${ }^{33}$ The dissipative properties - and, to some extent, rigidity - of the ELR coatings can be related to their water content. We plotted $\Delta D_{7}$ as a function of $\Delta f_{7} / 7$ (Figure 6), which indicates the dissipation caused by a unit of frequency (and, indirectly, mass).

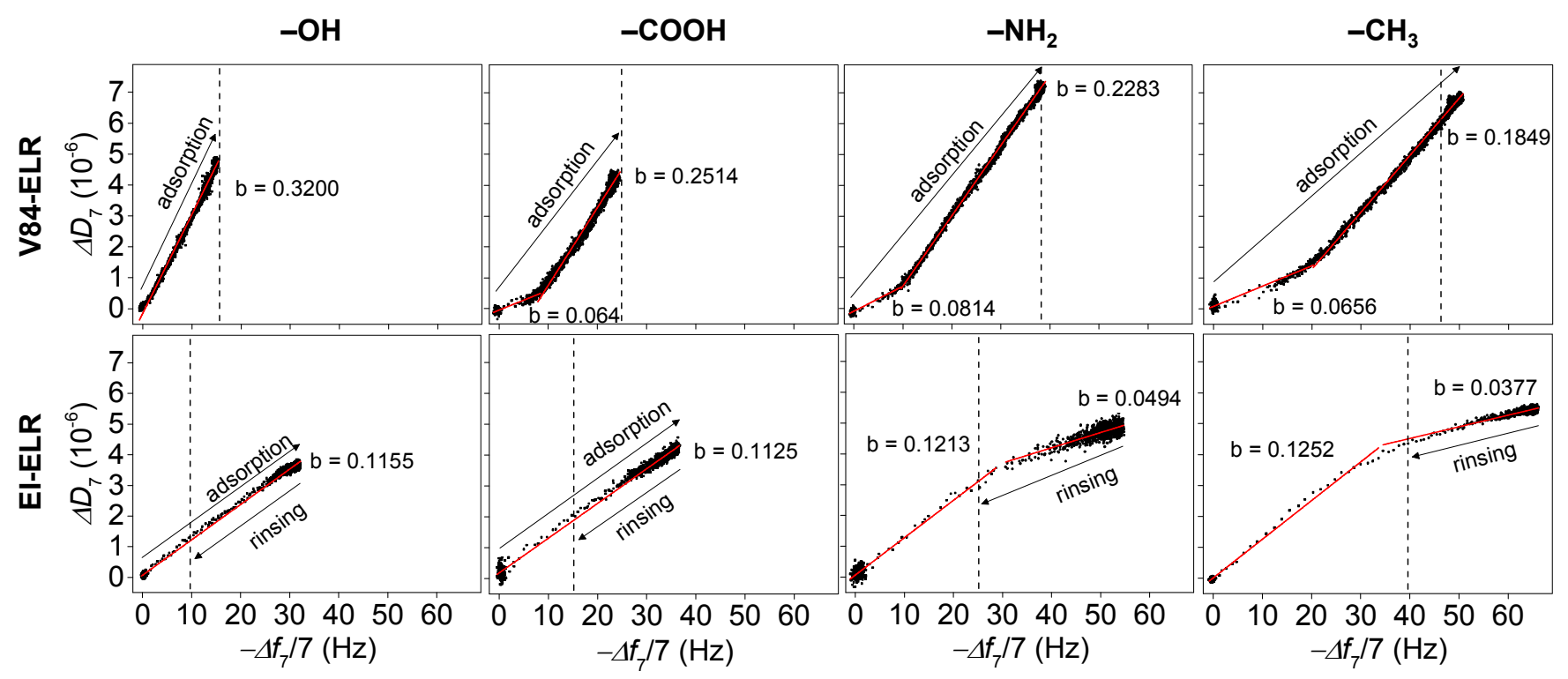

Figure 6. $\Delta D_{7} v s \Delta f_{7} / 7$ plots for the $7^{\text {th }}$ normalized harmonic. The presented data is based on the graphs shown in Figure 3. Red lines correspond to linear fittings according to the model $y=a+b x$, where $b$ is the slope of the linear approximation. The dashed lines represent the final $\Delta f_{7} / 7$ and $\Delta D_{7}$ at the end of adsorption and rinsing cycle. The arrows represent the direction of 
adsorption and rinsing (desorption). The rinsing stage of V84-ELR coatings is too small to be labelled.

In these graphs, time as an explicit parameter is eliminated. ${ }^{19,20,50}$ Small dissipation shifts are represented by small $\Delta D / \Delta f$ slopes (the $b$ value in the linear fitting model), whereas large dissipation shifts are characterized by large slopes. For V84-ELR assembled on OH-terminated substrates, a high slope was observed, indicating a high level of hydration. This result is consistent with the $H d$ value presented in Table 1. As the coatings became thicker $\left(\mathrm{COOH}, \mathrm{NH}_{2}\right.$, and $\mathrm{CH}_{3}$ surfaces), a second more dissipative slope emerged (i.e., large dissipation shifts in respect to frequency). Roach, Farrar and Perry previously described that the adsorption of fibrillar proteins starts with its long axis parallel to the surface and then rearrangement to a more perpendicular orientation to increase protein-protein interaction and surface concentration of protein. ${ }^{21}$ This model suggests that V84-ELR first bonded strongly to the substrate, covering it quickly leaving little room for water binding, and then reorganized into a more outwards extended conformation freeing additional areas for water molecules to bind, becoming softer.

EI-ELR coatings behaved differently. After rinsing, coatings assembled on all SAMs exhibited only one dissipative slope. With the thickest ones (on $\mathrm{NH}_{2}$ and $\mathrm{CH}_{3} \mathrm{SAMs}$ ) a second slope with relatively rigid features was observed, but ended up being rinsed (shown by the decrease of frequency and dissipation to those of the first slope). This temporary slope suggests the formation of two layers of EI-ELR and a more globular conformation than V84-ELR. ${ }^{21}$ The first is a strongly bonded layer of nanoaggregates driven by the specific ELR/SAM interactions described above, with no indication of conformational changes. The second is a less hydrated layer, weakly bonded to the first nanoaggregate assembly, probably stabilized by hydrogen 
bonds. Owing to the low thermodynamic affinity of this layer, rinsing leads to its desorption, leaving only the first layer bonded to the underlying SAM.

The analysis of the slopes at the end of the assembly and rinsing demonstrated that EI-ELR coatings are more rigid (low $b$ values) than V84-ELR ones (high $b$ values). The Sauerbrey areal mass of EI-ELR coatings, which assumes simplistically that they behave as pure rigid structures, is in agreement with this claim. No statistical differences were found when comparing the areal mass calculated using the Voigt-based viscoelastic model and the Sauerbrey model, which suggests that their properties resemble, to some extent, those of rigid coatings (Table S2, Figure S5). In the case of V84-ELR, the Voigt areal mass was statistically higher than the Sauerbrey areal mass on $\mathrm{NH}_{2}$ and $\mathrm{CH}_{3}$, which showcases viscoelastic behavior. These results confirm that ELRs can be designed to build coatings with tunable dissipative behavior.

With the aid of the AFM, we visualized the topography of the surfaces representing the thinnest (OH-terminated) and the thickest $\left(\mathrm{CH}_{3}\right.$-terminated) ELR coatings (Figures 7A and 7B).

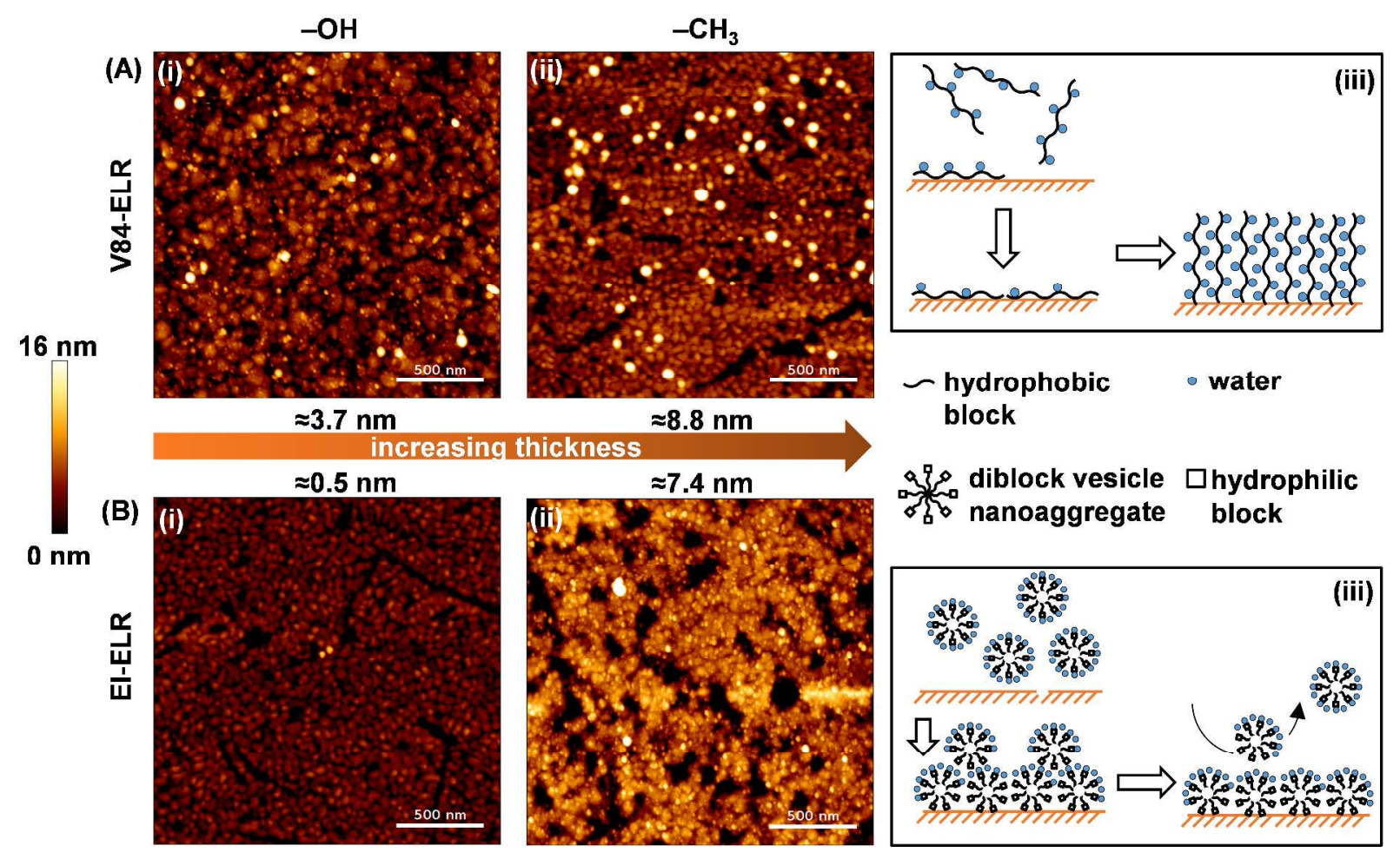


Figure 7. AFM imaging of (A) V84-ELR and (B) EI-ELR coatings, assembled on (i) OH and (ii) $\mathrm{CH}_{3}$-terminated surfaces, acquired under room temperature in air on a $2 \times 2 \mu \mathrm{m}^{2}$ area. The thickness values correspond to the average $T h_{Q C M-D}$ reported in Table 1, indicated for comparison sake. Scale bar: $500 \mathrm{~nm}$. The schemes (iii) depict the proposed adsorption mechanism for monoblock and diblock ELRs.

It is worth mentioning that these surfaces differ from the ones shown in Figure 2 in terms of substrate (thiol-modified gold instead of mica) and the fixation mode of ELRs onto it (surface adsorption instead of nanoaggregate droplet drying). The V84-ELR assembled on OH did not exhibit any significant topography feature (Figure 7A, i), as the ELR/OH interactions were the least favorable for assembly. In contrast, on $\mathrm{CH}_{3}$ surfaces, the roughness and localized structures of aggregated polypeptide was clear (Figure 7A, ii, seen as white spots), sharing similarities with the "islet"-like aspect of some polymeric multilayer formulations. ${ }^{51,52}$ Previously, an adsorption mechanism for fibrillar proteins has been described that can explain this observation. ${ }^{21}$ The rearrangement of the monoblock ELR into a perpendicular orientation can result in spatially distributed aggregates with highly dissipative behavior (Figure 7A, iii), and expose free uncoated sites. As for EI-ELR coatings on $\mathrm{OH}$ surfaces, no distinctive topographic features could be discerned. Small spherical particles were barely visible (Figure 7B, i) but those are consistent with the morphology of the gold grains on uncoated substrates (Figure S6). This is also supported by the low estimated thickness of the EI-ELR coatings assembled on $\mathrm{OH}$ substrates. On $\mathrm{CH}_{3}$ surfaces, EI-ELR nanoaggregates appear to cover a large surface area with only a few areas containing non-significant amounts of material (Figure 7B, ii, seen as black spots). This image also represents the topography of the first strongly bonded layer alone, as the second more rigid one should have been removed during rinsing (Figure 7B, iii). Together with 
the conclusion drawn from the QCM-D and MP-SPR, the AFM showed how each ELR was spread across the area of the underlying substrate and the dependence on the adsorption mechanism. Furthermore, the distinct topographies obtained for each of the ELRs let foresee that these polypeptides could be used to tune not only the mechanical properties of a surface but also its topography.

\section{CONCLUSIONS}

This work reports the feasibility to assemble polypeptide-based coatings with tunable surface physicochemical properties. We demonstrated that the affinity, the hydration, and conformation of ELR coatings can be induced by manipulating the amino acid composition and position within the polypeptide structure. The hydrophobic nature intrinsic to this class of polypeptides and their modification with THPC granted a good binding affinity to hydrophobic and positively charged SAMs, regardless of the ELR architecture. Thanks to the successful combination of the QCM-D, MP-SPR and AFM techniques, we determined that the monoblock V84-ELR adsorbs as conventional fibrillar proteins do, resulting in soft hydrated superficial coatings. In opposition, the adsorption of the amphiphilic diblock EI-ELR resembles that of vesicle systems and exhibits a more rigid block-oriented conformation.

We envisage that more complex designs can lead to the development of interfaces with higher levels of control of the surface mechanical properties for biomedical applications. As the surface of a device is the first contact with a biological environment, protein-based interfaces can result in a better biological integration of implantable systems, improve the adhesion and proliferation of mammalian cells, and enhance the cell penetrating capacity of drug delivery systems. Interfaces with tunable rigid or soft characteristics can be allied with the inclusion of bioactive 
sequences to promote all these functionalities. Furthermore, surfaces with controlled physicochemical properties will contribute to the development of Precision Medicine applications, including co-culture cell substrates with spatially-controlled stiffness, and patientdriven implantable devices.

\section{ASSOCIATED CONTENT}

Supporting Information. The following files are available free of charge.

Unmodified V84-ELR and EI-ELR amino acid sequences (Table S1), DSC scan of unmodified EI-ELR (Figure S1), $\Delta f_{n} / n$ and $\Delta D_{n}$ on alkanethiol-modified substrates for the $5^{\text {th }}, 7^{\text {th }}$ and $9^{\text {th }}$ harmonics for V84-ELR (Figure S2) and EI-ELR (Figure S3), Voigt and Sauerbrey areal masses estimations (Table S2), predicted mechanism of adsorption for V84-ELR on OH-terminated surfaces (Figure S4), plots of the Voigt and Sauerbrey areal masses with statistical significant differences indicated (Figure S5), AFM image of clean gold substrate modified with OH SAMs (Figure S6), height profile analysis on the surface of uncoated (Figure S7) and EI-ELR coated (Figure S8) on OH-terminated SAMs, image analysis based on the AFM profiles (Table S3) (PDF).

\section{AUTHOR INFORMATION}

\section{Corresponding Author}

*Rui R. Costa (e-mail): rui.costa@i3bs.uminho.pt

*Iva Pashkuleva (e-mail): pashkuleva@i3bs.uminho.pt

\section{Author Contributions}


The manuscript was written through contributions of all authors. All authors have given approval to the final version of the manuscript.

\section{ACKNOWLEDGMENTS}

The authors acknowledge financial support from "Fundação para a Ciência e Tecnologia" (grants SFRH/BPD/95446/2013 to RRC and IF/00032/2013 to IP), the Portuguese "Fundo Social Europeu" (FSE) and "Programa Operacional Capital Humano" (POCH), the European Commission (H2020 programme) through the projects ELASTISLET (NMP-2014-646075), CHEM2NATURE (TWINN-2015-692333), FORECAST (WIDESPREAD-2014-2-668983) and THE DISCOVERIES CTR (WIDESPREAD-01-2016-2017739572), MINECO of the Spanish Government (MAT2015-68901-R, MAT2016-78903-R), Junta de Castilla y León (VA015U16), the Spanish Ministry of Education, Culture and Sports (BOE-A-2015-12849, grant FPU15-00448 to MGP) and the co-founding from Consejería de Educación de la Junta de Castilla y León and Fondo Social Europeo (grant BOCYL-D-16112016-11 to MHG).

\section{REFERENCES}

(1) Dobson, C. M. Protein folding and misfolding. Nature 2003, 426, 884-890.

(2) Eaton, W. A.; Muñoz, V.; Hagen, S. J.; Jas, G. S.; Lapidus, L. J.; and, E. R. H.; Hofrichter, J. Fast Kinetics and Mechanisms in Protein Folding. Annu. Rev. Biophys. Biomol. Struct. 2000, 29, 327-359.

(3) Grantcharova, V.; Alm, E. J.; Baker, D.; Horwich, A. L. Mechanisms of protein folding. Curr. Opin. Struct. Biol. 2001, 11, 70-82. 
(4) Lee, D.; Redfern, O.; Orengo, C. Predicting protein function from sequence and structure. Nat. Rev. Mol. Cell Biol. 2007, 8, 995-1005.

(5) Leskinen, T.; Witos, J.; Valle-Delgado, J. J.; Lintinen, K.; Kostiainen, M.; Wiedmer, S. K.; Österberg, M.; Mattinen, M.-L. Adsorption of Proteins on Colloidal Lignin Particles for Advanced Biomaterials. Biomacromolecules 2017, 18, 2767-2776.

(6) Penna, M. J.; Mijajlovic, M.; Biggs, M. J. Molecular-Level Understanding of Protein Adsorption at the Interface between Water and a Strongly Interacting Uncharged Solid Surface. J. Am. Chem. Soc. 2014, 136, 5323-5331.

(7) Schönwälder, S. M. S.; Bally, F.; Heinke, L.; Azucena, C.; Bulut, Ö. D.; Heißler, S.; Kirschhöfer, F.; Gebauer, T. P.; Neffe, A. T.; Lendlein, A.; Brenner-Weiß, G.; Lahann, J.; Welle, A.; Overhage, J.; Wöll, C. Interaction of Human Plasma Proteins with Thin Gelatin-Based Hydrogel Films: A QCM-D and ToF-SIMS Study. Biomacromolecules 2014, 15, 2398-2406.

(8) Verde, A. V.; Acres, J. M.; Maranas, J. K. Investigating the Specificity of Peptide Adsorption on Gold Using Molecular Dynamics Simulations. Biomacromolecules 2009, 10, 2118-2128. (9) Wilson, C. J.; Clegg, R. E.; Leavesley, D. I.; Pearcy, M. J. Mediation of biomaterial-cell interactions by adsorbed proteins: a review. Tissue Eng. 2005, 11, 1-18.

(10) Pins, G. D.; Christiansen, D. L.; Patel, R.; Silver, F. H. Self-assembly of collagen fibers. Influence of fibrillar alignment and decorin on mechanical properties. Biophys. J. 1997, 73, 2164-2172.

(11) Vepari, C.; Kaplan, D. L. Silk as a Biomaterial. Prog. Polym. Sci. 2007, 32, 991-1007.

(12) Almine, J. F.; Bax, D. V.; Mithieux, S. M.; Nivison-Smith, L.; Rnjak, J.; Waterhouse, A.;

Wise, S. G.; Weiss, A. S. Elastin-based materials. Chem. Soc. Rev. 2010, 39, 3371-3379. 
(13) Li, N. K.; Quiroz, F. G.; Hall, C. K.; Chilkoti, A.; Yingling, Y. G. Molecular Description of the LCST Behavior of an Elastin-Like Polypeptide. Biomacromolecules 2014, 15, 3522-3530. (14) Rodríguez-Cabello, J. C.; Martín, L.; Girotti, A.; García-Arévalo, C.; Arias, F. J.; Alonso, M. Emerging applications of multifunctional elastin-like recombinamers. Nanomedicine 2010, 6 , 111-122.

(15) Urry, D. W. Molecular Machines: How Motion and Other Functions of Living Organisms Can Result from Reversible Chemical Changes. Angew. Chem., Int. Ed. 1993, 32, 819-841. (16) Costa, R. R.; Custódio, C. A.; Arias, F. J.; Rodríguez-Cabello, J. C.; Mano, J. F. Layer-byLayer Assembly of Chitosan and Recombinant Biopolymers into Biomimetic Coatings with Multiple Stimuli-Responsive Properties. Small 2011, 7, 2640-2649.

(17) Girotti, A.; Reguera, J.; Rodriguez-Cabello, J. C.; Arias, F. J.; Alonso, M.; Matestera, A. Design and bioproduction of a recombinant multi(bio)functional elastin-like protein polymer containing cell adhesion sequences for tissue engineering purposes. J. Mater. Sci.: Mater. Med. 2004, $15,479-84$.

(18) Prieto, S.; Shkilnyy, A.; Rumplasch, C.; Ribeiro, A.; Arias, F. J.; Rodríguez-Cabello, J. C.; Taubert, A. Biomimetic Calcium Phosphate Mineralization with Multifunctional Elastin-Like Recombinamers. Biomacromolecules 2011, 12, 1480-1486.

(19) Amorim, S.; Pires, R. A.; Costa, D. S. d.; Reis, R. L.; Pashkuleva, I. Interactions between Exogenous FGF-2 and Sulfonic Groups: in Situ Characterization and Impact on the Morphology of Human Adipose-Derived Stem Cells. Langmuir 2013, 29, 7983-7992.

(20) Höök, F.; Rodahl, M.; Kasemo, B.; Brzezinski, P. Structural changes in hemoglobin during adsorption to solid surfaces: Effects of pH, ionic strength, and ligand binding. Proc. Natl. Acad. Sci. U. S. A. 1998, 95, 12271-12276. 
(21) Roach, P.; Farrar, D.; Perry, C. C. Interpretation of Protein Adsorption: Surface-Induced Conformational Changes. J. Am. Chem. Soc. 2005, 127, 8168-8173.

(22) Liang, H.; Miranto, H.; Granqvist, N.; Sadowski, J. W.; Viitala, T.; Wang, B.; Yliperttula, M. Surface plasmon resonance instrument as a refractometer for liquids and ultrathin films. Sens. Actuators, B 2010, 149, 212-220.

(23) Teixeira, R.; Reis, R. L.; Pashkuleva, I. Influence of the sulfation degree of glycosaminoglycans on their multilayer assembly with poly-l-lysine. Colloids Surf., B 2016, 145, $567-575$.

(24) Wei, Q.; Becherer, T.; Angioletti-Uberti, S.; Dzubiella, J.; Wischke, C.; Neffe, A. T.; Lendlein, A.; Ballauff, M.; Haag, R. Protein Interactions with Polymer Coatings and Biomaterials. Angew. Chem., Int. Ed. 2014, 53, 8004-8031.

(25) Richter, R. P.; Brisson, A. R. Following the Formation of Supported Lipid Bilayers on Mica: A Study Combining AFM, QCM-D, and Ellipsometry. Biophys. J. 2005, 88, 3422-3433. (26) Thyparambil, A. A.; Wei, Y.; Latour, R. A. Determination of Peptide-Surface Adsorption Free Energy for Material Surfaces Not Conducive to SPR or QCM using AFM. Langmuir 2012, $28,5687-5694$.

(27) Wang, C.; Kittle, J. D.; Qian, C.; Roman, M.; Esker, A. R. Chitinase Activity on Amorphous Chitin Thin Films: A Quartz Crystal Microbalance with Dissipation Monitoring and Atomic Force Microscopy Study. Biomacromolecules 2013, 14, 2622-2628.

(28) Arima, Y.; Iwata, H. Effects of surface functional groups on protein adsorption and subsequent cell adhesion using self-assembled monolayers. J. Mater. Chem. 2007, 17, 40794087. 
(29) Benesch, J.; Mano, J. F.; Reis, R. L. Analysing protein competition on self-assembled mono-layers studied with quartz crystal microbalance. Acta Biomater. 2010, 6, 3499-3505. (30) da Costa, D. S.; Pires, R. A.; Frias, A. M.; Reis, R. L.; Pashkuleva, I. Sulfonic groups induce formation of filopodia in mesenchymal stem cells. J. Mater. Chem. 2012, 22, 7172-7178.

(31) Love, J. C.; Estroff, L. A.; Kriebel, J. K.; Nuzzo, R. G.; Whitesides, G. M. Self-Assembled Monolayers of Thiolates on Metals as a Form of Nanotechnology. Chem. Rev. 2005, 105, 11031170.

(32) Voinova, M. V.; Rodahl, M.; Jonson, M.; Kasemo, B. Viscoelastic Acoustic Response of Layered Polymer Films at Fluid-Solid Interfaces: Continuum Mechanics Approach. Phys. Scr. 1999, 59, 391.

(33) Costa, R. R.; Testera, A. M.; Arias, F. J.; Rodríguez-Cabello, J. C.; Mano, J. F. Layer-byLayer Film Growth Using Polysaccharides and Recombinant Polypeptides: A Combinatorial Approach. J. Phys. Chem. B 2013, 117, 6839-6848.

(34) Dutta, A. K.; Belfort, G. Adsorbed Gels versus Brushes: Viscoelastic Differences. Langmuir 2007, 23, 3088-3094.

(35) Weber, N.; Pesnell, A.; Bolikal, D.; Zeltinger, J.; Kohn, J. Viscoelastic Properties of Fibrinogen Adsorbed to the Surface of Biomaterials Used in Blood-Contacting Medical Devices. Langmuir 2007, 23, 3298-3304.

(36) Sauerbrey, G. Verwendung von Schwingquarzen zur Wägung dünner Schichten und zur Mikrowägung. Zeitschrift für Physik 1959, 155, 206-222.

(37) Girotti, A.; Reguera, J.; Arias, F. J.; Alonso, M.; Testera, A. M.; Rodríguez-Cabello, J. C. Influence of the Molecular Weight on the Inverse Temperature Transition of a Model 
Genetically Engineered Elastin-like pH-Responsive Polymer. Macromolecules 2004, 37, 33963400 .

(38) Rodriguez-Cabello, J. C.; Prieto, S.; Reguera, J.; Arias, F. J.; Ribeiro, A. Biofunctional design of elastin-like polymers for advanced applications in nanobiotechnology. J. Biomater. Sci., Polym. Ed. 2007, 18, 269-86.

(39) García-Arévalo, C.; Bermejo-Martín, J. F.; Rico, L.; Iglesias, V.; Martín, L.; RodríguezCabello, J. C.; Arias, F. J. Immunomodulatory Nanoparticles from Elastin-Like Recombinamers: Single-Molecules for Tuberculosis Vaccine Development. Mol. Pharmaceutics 2013, 10, 586597.

(40) Meyer, D. E.; Chilkoti, A. Quantification of the Effects of Chain Length and Concentration on the Thermal Behavior of Elastin-like Polypeptides. Biomacromolecules 2004, 5, 846-851.

(41) Ribeiro, A.; Arias, F. J.; Reguera, J.; Alonso, M.; Rodríguez-Cabello, J. C. Influence of the Amino-Acid Sequence on the Inverse Temperature Transition of Elastin-Like Polymers.

Biophys. J. 2009, 97, 312-320.

(42) Mrksich, M.; Whitesides, G. M. Using Self-Assembled Monolayers to Understand the Interactions of Man-made Surfaces with Proteins and Cells. Annu. Rev. Biophys. Biomol. Struct. 1996, 25, 55-78.

(43) Pfeiffer, I.; Petronis, S.; Köper, I.; Kasemo, B.; Zäch, M. Vesicle Adsorption and Phospholipid Bilayer Formation on Topographically and Chemically Nanostructured Surfaces. $J$. Phys. Chem. B 2010, 114, 4623-4631.

(44) Satulovsky, J.; Carignano, M. A.; Szleifer, I. Kinetic and thermodynamic control of protein adsorption. Proc. Natl. Acad. Sci. U. S. A. 2000, 97, 9037-9041. 
(45) Rodríguez-Cabello, J. C.; Reguera, J.; Alonso, M.; Parker, T. M.; McPherson, D. T.; Urry, D. W. Endothermic and exothermic components of an inverse temperature transition for hydrophobic association by TMDSC. Chem. Phys. Lett. 2004, 388, 127-131.

(46) Fears, K. P.; Gonzalez-Begne, M.; Love, C. T.; Day, D. E.; Koo, H. Surface-Induced Changes in the Conformation and Glucan Production of Glucosyltransferase Adsorbed on Saliva-Coated Hydroxyapatite. Langmuir 2015, 31, 4654-4662.

(47) Secundo, F. Conformational changes of enzymes upon immobilisation. Chem. Soc. Rev. 2013, 42, 6250-6261.

(48) Fang, F.; Szleifer, I. Kinetics and Thermodynamics of Protein Adsorption: A Generalized Molecular Theoretical Approach. Biophys. J. 2001, 80, 2568-2589.

(49) Neff, H.; Laborde, H. M.; Lima, A. M. N. Periodic protein adsorption at the gold/biotin aqueous solution interface: evidence of kinetics with time delay. Sci. Rep. 2016, 6, 36232. (50) Leite, Á. J.; Costa, R. R.; Costa, A. M. S.; Maciel, J. S.; Costa, J. F. G.; de Paula, R. C. M.; Mano, J. F. The potential of cashew gum functionalization as building blocks for layer-by-layer films. Carbohydr. Polym. 2017, 174, 849-857.

(51) Cardoso, M. J.; Caridade, S. G.; Costa, R. R.; Mano, J. F. Enzymatic Degradation of Polysaccharide-Based Layer-by-Layer Structures. Biomacromolecules 2016, 17, 1347-1357. (52) Richert, L.; Lavalle, P.; Payan, E.; Shu, X. Z.; Prestwich, G. D.; Stoltz, J.-F.; Schaaf, P.; Voegel, J.-C.; Picart, C. Layer by Layer Buildup of Polysaccharide Films: Physical Chemistry and Cellular Adhesion Aspects. Langmuir 2004, 20, 448-458. 


\section{GRAPHICAL TABLE OF CONTENTS}

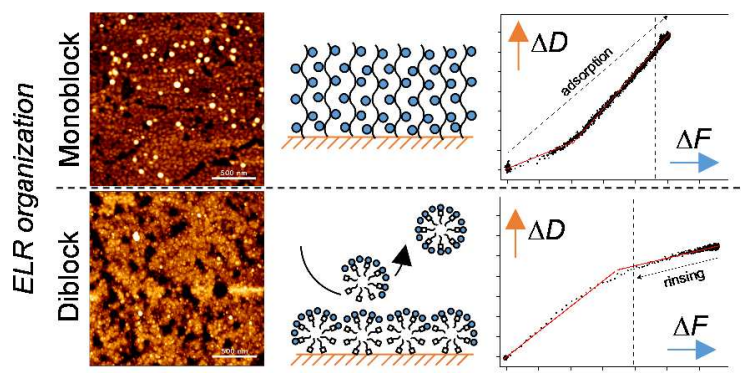

